We respectfully suggest that there is an urgent need to establish the specialty of palliative medicine in the United States and to avoid the temptation to view physician-assisted death as an alternative to meticulous palliative care.

ILORA G. FINLAY, M.D. JAMES GILBERT, M.D.

FIONA RANDALL, M.D.

Association for Palliative

Southampton SO17 IDL, United Kingdom

Medicine of Great Britain and Ireland

1. Submission from the Ethics Group of the Association for Palliative Medicine to the Select Committee of the House of Lords on Medical Ethics. Southampton, England: Association for Palliative Medicine, 1993:21.

2. Report of the Select Committee on Medical Ethics, House of Lords. HI Paper 21-I. London: Her Majesty's Stationery Office, 1994:26, 48.

3. Walton J. House of Lords Official Report 1994;554(83):1345.

4. Cessation of treatment, non-resuscitation, aiding suicide and euthanasia. In: British Medical Association, Ethics, Science and Information Division. Medical ethics today: its practice and philosophy. London: BMJ Publishing, 1993: 175-7.

The authors reply:

To the Editor: Callahan erroneously concludes that our recommended policy for regulating physician-assisted death would be a charade. We expect that physicians who are now prepared to risk legal and professional sanctions by responding to their patients' requests for help in dying will welcome a legal option and comply with stipulated safeguards. Furthermore, we recommend serious penalties for physicians found to assist in patients' deaths without complying with regulatory procedures. We do not propose any ideological test for palliative-care consultants charged with oversight, but they must have open minds about the reasonableness of physicianassisted death in particular cases. Their independence and impartiality would derive from their lack of collegial affiliation with treating physicians and their responsibility for ensuring that physician-assisted death occurred only in the context of a thorough palliative-care assessment and the careful consideration of alternatives.

Feucht et al. question the ethical basis of our position. We focused our article on the design of public policy rather than on the ethical grounds for physician-assisted dying, which we have addressed in detail in other publications. ${ }^{1-3}$

We join Lynn in deploring the lack of adequate health care and social services for disadvantaged Americans. Improving access to palliative care should be a high priority, and we have much to learn about this from the United Kingdom, as Finlay et al. indicate. We disagree, however, with their statement that the time is not right to debate the regulation of physician-assisted death. Dying patients who suffer intolerably without obtaining satisfactory relief with palliative treatment currently face the unacceptable alternatives of enduring needless torment, attempting suicide by themselves, or secretly seeking the aid of physicians prepared to risk helping them end their lives. The status quo is unfair to these patients, their families, and their physicians. Furthermore, the recent referendum in Oregon legalizing physician-assisted suicide and pending judicial review elsewhere of laws prohibiting this practice make it timely to debate the optimal regulatory policy.

We agree with Billings and Block that psychiatric consultation is an important consideration in assessing requests for physician-assisted death. Although we do not favor limiting this option to patients who are imminently dying, we agree that it should not be made available in the early stages of terminal conditions, when patients can still maintain a decent quality of life with the help of competent medical care.

Palliative care works very well for most dying patients, but neither clinical experience nor research indicates that such care can adequately relieve the pain and suffering of all such patients. ${ }^{4}$ Physician-assisted death is justifiable only for the minority of competent, incurably ill patients who resolutely prefer death to an intolerable quality of life. The aim of our recommended policy is both to promote palliative care and to make available as a last resort the option of voluntary physician-assisted death, subject to appropriate safeguards.

Franklin G. Miller, Ph.D. University of Virginia School of Medicine

Charlottesville, VA 22908

Timothy E. Quill, M.D. Genesee Hospital

Rochester, NY 14607$$
\text { Genesee Hospital }
$$

1. Quill TE. Death and dignity: making choices and taking charge. New York: W.W. Norton, 1993.

2. Brody $H$. Assisted death - a compassionate response to a medical failure. N Engl J Med 1992;327:1384-8.

3. Miller FG, Fletcher JC. The case for legalized euthanasia. Perspect Biol Med 1993;36:159-76.

4. Kasting GA. The nonnecessity of euthanasia. In: Humber JM, Almeder RF, Kasting GA, eds. Physician-assisted death. Totowa, N.J.: Humana Press, 1994:24-45.

\section{HEPA RESPIRATORS AND TUBERCULOSIS IN HOSPITAL WORKERS}

To the Editor: Adal et al. (July 21 issue) ${ }^{1}$ demonstrate that at the University of Virginia Hospital, where the incidence of tuberculosis is low, the infection controls already instituted may be sufficient and the cost of adding respirators with highefficiency particulate air filters (HEPA respirators) for their 3852 workers is impressively high. The situation is different at our hospital, Lincoln Medical and Mental Health Center in South Bronx, New York. In contrast to their figure of 11 patients with documented tuberculosis per year, we have over 160 such patients per year, of whom approximately 30 percent have multidrug-resistant tuberculosis. As a result, in about 160 of our employees the purified-protein-derivative (PPD) skin test became positive during 1992 and 1993, requiring expensive prophylactic treatment.

At the University of Virginia Hospital there is probably no more than one patient with suspected tuberculosis on a given floor, whereas we have an entire floor of such patients. At our hospital, it is unlikely that patients on the tuberculosis ward will have the benefit of 50 visits by hospital workers per day. Rather, we estimate that the number of visits ranges from 10 to 15 per day. All patients are seen by the same dedicated medical and nursing staff on the same medical round, and only one mask is used per employee per medical round. We estimate that about 50 to 100 workers are exposed to tuberculosis each day. If each one uses one mask per day, the yearly cost could be less than $\$ 400,000$. Since the rate of PPD conversion is so high, the costs of annual examinations are unavoidable at our institution and should not be added to the cost of HEPA respirators.

Policy makers should not use the inflated costs reported by Adal et al. to cut the budget for new protective measures. 
The war against tuberculosis is far from over, and we have a lot to lose in this battle.

Eitan SOBEL, M.D. Lincoln Medical

\section{Bronx, NY 10541} and Mental Health Genter

1. Adal KA, Anglim AM, Palumbo CL, Titus MG, Coyner BJ, Farr BM. The use of high-efficiency particulate air-filter respirators to protect hospital workers from tuberculosis — a cost-effective analysis. N Engl J Med 1994;331:16973.

To the Editor: At our 800-bed university-associated hospital in Winston-Salem, North Carolina, patients with tuberculosis are isolated in rooms with negative-pressure, 100 percent external exhaust, and workers entering these rooms wear midgrade surgical masks whose fit has not been tested. During the past academic year (July 1993 to June 1994), we had 14 cases of tuberculosis, and the PPD-conversion rate was 0.1 percent among our workers (5 of 3806). All five workers with conversion to a positive PPD skin test were evaluated for exposures to any of the 14 patients with tuberculosis; none were documented. During the previous four years, all exposures of personnel to patients with tuberculosis have been evaluated by the PPD skin test; no conversions have occurred. Thus, at our institution the figures provided by Adal et al. would underestimate the cost of preventing a single case of occupationally acquired tuberculosis.

ROBERT J. SHERERTZ, M.D. Bowman Gray School of Medicine of Wake Forest University

Stephen A. STREed, M.S. North Carolina

Winston-Salem, NC 27157 Baptist Hospitals

To the Editor: Adal et al. calculate that it would cost $\$ 1.3$ million to $\$ 18.5$ million to prevent one case of tuberculosis in workers at their hospital through the use of HEPA respirators. The use of HEPA respirators is recommended by the draft guidelines of the Centers for Disease Control and Prevention (CDC) ${ }^{1}$ and required by the Occupational Safety and Health Administration. ${ }^{2}$ These respirators have a high filter efficiency for mycobacterial aerosols (>99.99 percent) ${ }^{3}$ and with proper fitting should have less leakage around the face seal than the submicron surgical mask.

As part of a pilot program our hospital personnel underwent a 45-minute training session in the proper use of HEPA respirators conducted by an industrial hygienist and an infection-control clinician. All subjects passed the initial fit test with the 3M HEPA respirator (model 9970) and the irritantfume qualitative fit test. Twelve employees were later retested after using these masks during clinical activities (mean, 4.8 uses), and four (33 percent) failed the irritant-fume fit test because of leakage around the face seal. Five employees were retested a second time after additional use of their respirators, and two of them again failed the test.

We conclude that despite intensive training a substantial number of employees fail follow-up fit tests. These results may have been due to the deformation of the mask during use or to employees' failure to adjust the mask properly for a tight seal. Any leakage around the face seal will nullify the slight advantage offered by HEPA respirators.

If additional studies find that face-seal leakage of HEPA respirators is common despite intensive training of workers, then the use of these expensive respirators will not be of even theoretical benefit in preventing tuberculosis in health care workers.

VICKIE BROWN, R.N. GAROLYN Bishop, M.S.P.H. William A. Rutala, Ph.D., M.P.H. DAVID J. WEBER, M.D., M.P.H. University of North Carolina Hospitals

1. Department of Health and Human Services, Centers for Disease Control and Prevention. Draft guidelines for preventing the transmission of tuberculosis in health-care facilities, second edition: notice of comment period. Fed Regist 1993;58(195):52810-54.

2. Enforcement policy and procedures for occupational exposure to tuberculosis. Occupational Safety and Health Administration Enforcement document. Washington, D.C.: Department of Labor, October 8, 1993.

3. Chen S-K, Vesley D, Brosseau LM, Vincent JH. Evaluation of single-use masks and respirators for protection of health care workers against mycobacterial aerosols. Am J Infect Control 1994;22:65-74.

The authors reply:

To the Editor: Dr. Sobel indicates that his tuberculosis ward has a high rate of conversion of the PPD test and suggests that the use of HEPA respirators will prevent this, but there are no epidemiologic data demonstrating the effectiveness of HEPA respirators. The CDC has reported successful control of outbreaks of multidrug-resistant tuberculosis in New York hospitals without the use of HEPA respirators.' We recently surveyed resident physicians in internal medicine at the University of Virginia who had worked at an affiliated tuberculosis hospital that used negative-pressure ventilation, ultraviolet lights, and simple isolation masks for protection. Fifty-two responding physicians did 70 six-week rotations on tuberculosis wards without a single conversion (95 percent confidence interval, 0 to 1 conversion every 8 physician-years). These data suggest that transmission is unlikely with the use of simple isolation masks in tuberculosis wards if conventional administrative and engineering controls are used correctly. ${ }^{2}$ Similar results have been reported by the tuberculosis service at the National Jewish Center for Respiratory Health and Immunology.

We agree with Dr. Sherertz and Mr. Streed that our cost analysis probably underestimated the average cost of preventing a single case of occupationally acquired tuberculosis. After carefully analyzing the rate of conversions over an additional 12-month period, we have revised our calculations to incorporate the assumption that HEPA respirators may be able to prevent one PPD conversion every 24 months. Thus, it would take a minimum of 82 years on average to prevent a single case of tuberculosis at our hospital at a cost of $\$ 2.6 \mathrm{mil}$ lion to $\$ 36.9$ million for HEPA respirators and medical evaluation, training, and fit testing before their use.

We agree with Ms. Brown and colleagues that the proposed requirement for fit testing of HEPA respirators should be scientifically validated, preferably before a policy decision is made. Others have reported problems with the reliability of fit-testing results. ${ }^{3}$

Until data from additional epidemiologic studies are available, we advocate the use of dust-mist respirators, which have been used successfully with conventional administrative and engineering measures to control epidemics of multidrugresistant tuberculosis in New York and have a filtering eff- 
ciency of 98 percent for mycobacteria. ${ }^{4}$ Health care workers can be instructed to apply these masks tightly to the face without special training sessions. Medical evaluation appears unnecessary for dust-mist respirators because of their similarity to simple isolation masks.

KARIM A. ADAL, M.D., M.S. ANNE M. ANGLIM, M.D., M.S. BARRY M. FARR, M.D., M.SC. University of Virginia Charlottesville, VA 22908 Health Sciences Cienter

1. Maloney S, Pearson M, Gordon M, Castillo RD, Boyle J, Jarvis W. Nosocomial multi-drug resistant tuberculosis revisited: assessing the efficacy of recommended control measures in preventing transmission to patients and health care workers. Ann Intern Med (in press).

2. Jernigan JA, Adal KA, Anglim AM, Byers KE, Farr BM. Mycobacterium tuberculosis transmission rates in a sanitarium: implications for new preventive guidelines. Am J Infect Control (in press).

3. Segal-Maurer S, Kalkut GE. Environmental control of tuberculosis: continuing controversy. Clin Infect Dis 1994;19:299-308.

4. Chen S-K, Vesley D, Brosseau LM, Vincent JH. Evaluation of single-use masks and respirators for protection of health care workers against mycobacterial aerosols. Am J Infect Control 1994;22:65-74.

\section{GLINICAL PROBLEM-SOLVING: AN ANATOMY LESSON}

To the Editor: I greatly enjoyed reading "An Anatomy Lesson" by Dr. Duffy (Aug. 4 issue). ${ }^{.}$As a resident physician I appreciate and learn a great deal from such practical clinical vignettes.

After outlining the importance of the retroperitoneal lymphatic drainage system of the testicles, however, Dr. Duffy concludes by noting the "anatomical association between the retroperitoneum and the scrotum." In fact, the lymphatics of the scrotum (along with those of the tunica vaginalis) drain to the superficial inguinal lymph nodes, as demonstrated by the anasarca of elephantiasis. This distinction can be important in differentiating testicular from nontesticular disease in the swollen scrotum.

Manchester, MO 63011

David C. Youmans, M.D. 776 Berquist Dr.

1. Duffy TP. An anatomy lesson. N Engl J Med 1994;331:318-20.

\section{Dr. Duffy replies:}

To the Editor: Dr. Youmans is correct about the pattern of drainage from the scrotum; the text should read "the anatomical association between the retroperitoneum and the contents of the scrotum." However, the purpose of the "Anatomy Lesson" was not simply to draw the reader's attention to the dissecting-room exercises of long ago but to illustrate that a thorough physical examination, including the genitalia, often provides critical information.

The loss of testicular pain sensation was a clue to tabes dorsalis in the past, and epididymal swelling was suggestive of tuberculosis. Even today, the presence of testicular pain may be the clue to an otherwise occult vasculitis, and the testes remain the site of the most common malignant tumor in young men. The failure to examine the scrotum and its contents may lead one to overlook a finding relevant not only to the retroperitoneum but also to systemic diseases elsewhere in the body.

Thomas P. Duffy, M.D.

Yale University

New Haven, CT 06510

\section{THE TYRANNY OF HEALTH}

To the Editor: Reading Dr. Fitzgerald's article, "The Tyranny of Health" (July 21 issue), ${ }^{1}$ reminded me of a comment a patient once made to me. After I had berated the patient for his obvious failure to comply with my recommendations to correct his "misbehavior," he said, "You know, doctor, there is more to life than good health." These words have helped me rein in my sometimes overzealous attempts to force patients into that glorious state of wellness and maintain a more realistic approach to the best possible state of health.

Lewis E. Foxhall, M.D. University of Texas

Houston, TX 77030

M.D. Anderson Cancer Center

1. Fitzgerald FT. The tyranny of health. N Engl J Med 1994;331:196-8.

To the Editor: The increasing criticism of unhealthy lifestyles is a direct result of spreading the responsibility for health care costs to the general public. Canada's tax-funded system of medical care brought about this change long before the current broad definition of health existed. When taxes are high, the cost of medical care is increasing, and rationing of services is introduced - as is the case in Canada - the public will inevitably criticize those who abuse their health and cost the system more.

Saskatoon, SK S7H 4B6, Canada

T.B. MaGLaChlan, M.D. 408 Garrison Cres.

To the Editor: . . . Medicine in America is undergoing a revolution that will change the approach to health care from a hodgepodge of treatments to a true system focused on health as the measured outcome. Strategies for behavioral change will be the pillars of this new house of medicine. There is absolutely no reason, scientific or moral, to shrink from the use of these tools of culture in performing our art.

Rochester, NY 14625-1507

George W. AnstadT, M.D. 75 Panorama Trail

To the Editor: I strongly agree with Fitzgerald that we must spend more time helping patients cope with the reality of illness and the common tragedies of life. However, I am concerned by the message that physicians should downplay issues such as domestic violence, child abuse, and substance abuse because these are personal actions that a physician should not attempt to control. On the contrary, these topics are among the most important issues the primary care physician can touch on during a brief office visit. We may not be any more qualified than other people to address social ills, yet our unique position, which makes us privy to personal information rarely shared with anyone else, mandates that we not ignore these serious threats to health. By equating life with fate, Dr. Fitzgerald undermines the power of individual people to control their own health.

Torrance, CA 90502

AlBert DiPiero, M.D. Harbor-UCLA Medical Center

To the Editor: Dr. Fitzgerald overlooks the fact that people's lifestyles also have a substantial effect on society. For instance, smoking-related problems generate over $\$ 100$ billion in health care expenditures annually. The average lifetime 